Linha D'Água (Online), São Paulo, v. 33, n. 1, p. 31-48, jan.-abr. 2020

\title{
ABORDAGEM SEMÂNTICA E MORFOLÓGICA A TERMOS INFORMÁTICOS NUM DICIONÁRIO BILINGUE PORTUGUÊS EUROPEU - ÁRABE PADRÃO
}

\author{
SEMANTIC AND MORPHOLOGICAL APPROACH TO COMPUTER TERMS IN \\ A BILINGUAL DICTIONARY PORTUGUESE EUROPEAN - ARABIC STANDARD
}

\author{
Abdesslam Okab* \\ Universidade Mohammed V, Rabat, Marrocos
}

\begin{abstract}
Resumo: Este artigo aborda a semântica e a morfologia de termos de uso frequente na informática, numa perspetivação bilingue Português Europeu - Árabe Padrão. Nele foram tratadas 20 unidades terminológicas, todas emprestadas à língua predominante neste domínio de experiência, o inglês, e traduzidas literalmente para o árabe padronizado. Foi aplicada a estas unidades, previamente agrupadas em conjuntos terminológicos, a análise componencial de Pottier, para decompor a significação que revela a natureza semântica dos seus conceitos. A análise morfológica só constitui um aspeto formal que completa a parte semântica, no caso do português, com o intuito de descrever 0 grau do aportuguesamento, quando existe variação de forma nos termos envolvidos. Quanto cos sintagmas terminológicos do árabe em foco, que correspondem aos empréstimos crudos do português como língua de partida e que são decalques semânticos, esses estão acompanhados, no corpus de exemplificação, das descrições gramaticais das bases de unidades simples das quais derivam.
\end{abstract}

Palavras-chave: Interfaces morfológico-semânticas; modelo componencial; quadros sémicos; subcampos terminológicos; semântica terminológica.

\begin{abstract}
This article discusses the semantics and morphology of commonly used terms in computer science, from a bilingual perspective related to European Portuguese - Standard Arabic. 20 terminological units were carried out, being all of them borrowed from the predominant language in this domain of experience, English, and translated literally by standard Arabic. They were applied to these units, previously grouped in terminological sets, using Pottier's component analysis to decompose the meaning that reveals the semantic nature of their concepts. The morphological analysis is only a formal aspect that completes the semantic part, in the case of Portuguese, with the purpose of describing the degree of morphological adaptation when variation of form in the terms involved exists. As for the Arabic terminological phrases in focus, which correspond to the crude borrowings of Portuguese as a source language and which are semantic decals, they are accompanied, in the corpus of exemplification, by the grammatical descriptions of the simple base units from which they derive.
\end{abstract}

Keywords: Morphological-Semantic Interfaces; Compositional Model; Semic Frames; Terminological Subfields; Terminological Semantics.

* Professor do Instituto de Estudos Hispano-Lusófonos, Universidade Mohammed V - UM5, Rabat, Marrocos; a.okab854@gmail.com

http://dx.doi.org/10.11606/issn.2236-4242.v33i1p31-48

Todo conteúdo da Linha D'Água está sob Licença Creative Commons Attribution-NonCommercial 4.0 International License 
Linha D’Água (Online), São Paulo, v. 33, n. 1, p. 31-48, jan.-abr. 2020

\section{Introdução}

Tratar os termos da informática numa perspetivação bilingue Português - Árabe coloca a questão de terminologia num domínio duma ciência publicada predominantemente em língua inglesa desde o nascimento e cujos termos têm sido emprestados ou traduzidos da língua doadora por muitos idiomas no mundo.

Neste trabalho, pretendemos estudar os termos informáticos de uso frequente na elaboração dum dicionário bilingue Português Europeu - Árabe Padrão, tendo em conta as interfaces morfológico-semânticas que existem nas equivalências entre ambas as línguas em foco, para dar conta de como cada uma acolhe as unidades terminológicas do domínio da experiência da informática e quais equivalentes correspondem no árabe padrão à terminologia informática comum do português de Portugal como língua de partida num dicionário bilingue, destinado a universitários e profissionais da tradução.

\section{Apresentação do corpus de exemplificação}

Para a análise em causa, todos os candidatos terminológicos, que foram selecionados propositadamente, pertencem a um vocabulário que reflete um uso abrangente que inclui pessoas não especialistas na área da informática. Trata-se dum conjunto de vinte termos que foram coletados no início para a língua de partida, o português europeu, no Dicionário da Língua Portuguesa de Porto Editora, para mais tarde serem contextualizados a partir de exemplos de textos publicitários e de imprensa, assim como da língua numérica. Após esta primeira etapa, procurei, com ajuda de glossários terminológicos bilingues Francês - Árabe / Inglês - Árabe e trilingues Francês - Inglês - Árabe, os equivalentes das vinte unidades terminológicas que constituem o objeto de nossa pesquisa. $\mathrm{Na}$ sua contextualização, os exemplos foram extraídos de textos digitalizados de finalidade informativa ou publicitária e de livros destinados a não especialistas.

1 árabe padrão é a língua usada nos meios de comunicação de massas, nos discursos oficiais e religiosos, a língua literária e científica dos países árabes, que possuem, para além dela, falas locais peculiares que utilizam só na comunicação familiar e do dia-a-dia entre eles.

OKAB, A. Abordagem semântica e morfológica a termos informáticos num dicionário bilingue Português Europeu - Árabe Padrão 
Linha D'Água (Online), São Paulo, v. 33, n. 1, p. 31-48, jan.-abr. 2020

Eis a seguir os termos - entradas do português, língua de partida (LP), e do árabe, língua de chegada (LC) com as categorias gramaticais, as definições e os contextos de uso, distribuídos nestes sete subcampos terminológicos:

1. Elementos físicos dum computador:

\begin{tabular}{|c|c|}
\hline Português & Árabe \\
\hline $\begin{array}{l}\text { hardware [ar' dwer] n.m. conjunto dos } \\
\text { elementos físicos de um computador, que } \\
\text { inclui o dispositivo principal e os periféricos } \\
\text { ( como teclado, monitor e impressora): } \\
\text { «hardware» e «software» são essenciais. A } \\
\text { maior parte da verba vai para a aquisição } \\
\text { de «hardware». } \\
\text { software [so'ftwer] n.m. conjunto de meios } \\
\text { não materiais (em oposição a hardware) } \\
\text { que servem para o tratamento automático da } \\
\text { informação e permitem o «diálogo» entre } \\
\text { o homem e o computador. O vocábulo } \\
\text { software é usado para designar a parte } \\
\text { lógica que fornece as directivas para o } \\
\text { conjunto de hardwares presentes num } \\
\text { determinado dispositivo. } \\
\text { chip ['Jip] n.m. circuito integrado que } \\
\text { tem como suporte uma pastilha de silício } \\
\text { ou outro material semicondutor no qual } \\
\text { são gravados ou inseridos componentes } \\
\text { eletrónicos que, em conjunto, desempenham } \\
\text { uma ou mais funções. Para trocar o chip } \\
\text { danificado, vendem-se chips retirados de } \\
\text { outros computadores. }\end{array}$ & 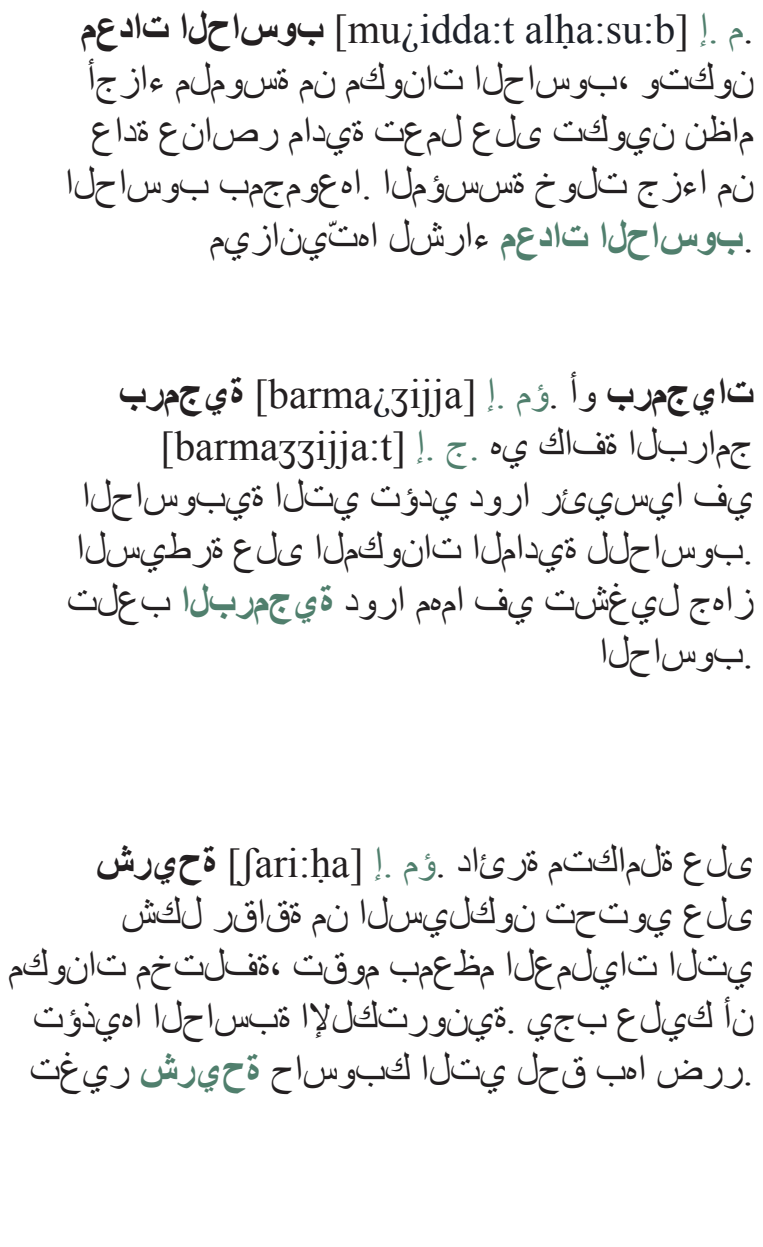 \\
\hline
\end{tabular}

OKAB, A. Abordagem semântica e morfológica a termos informáticos num dicionário bilingue Português Europeu - Árabe Padrão 
Linha D’Água (Online), São Paulo, v. 33, n. 1, p. 31-48, jan.-abr. 2020

2. Interfaces gráficas e sinais:

\begin{tabular}{|c|c|}
\hline Português & Árabe \\
\hline $\begin{array}{l}\left.\text { desktop [d } \varepsilon \int \mathrm{k}^{\prime} \mathrm{t} \supset \mathrm{p}\right] n . m \text {. parte da interface } \\
\text { gráfica que mostra ícones que representam } \\
\text { objetos comuns em ambientes de trabalho } \\
\text { (como documentos, arquivos e pastas). É } \\
\text { bastante frequente os usuários deixarem no } \\
\text { desktop atalhos para os programas mais } \\
\text { utilizados. }\end{array}$ & 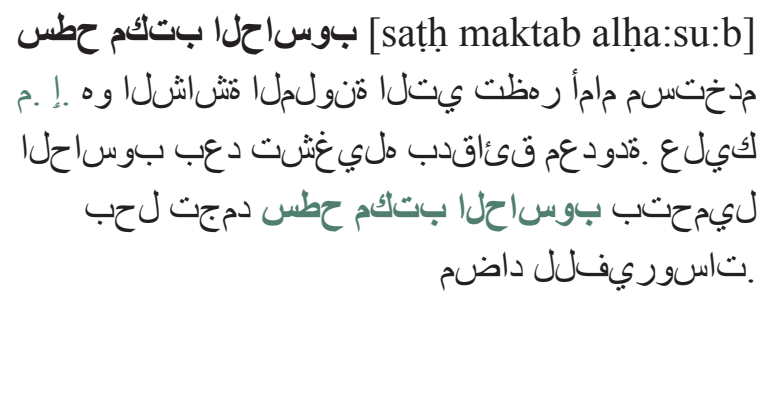 \\
\hline $\begin{array}{l}\text { arroba [e'Robe] n.f. sinal gráfico (@), usado } \\
\text { nos endereços de correio eletrónico para } \\
\text { separar o nome do utilizador do endereço } \\
\text { propriamente dito.É por isso que o nome da } \\
\text { exposição inclui a arroba@, o símbolo do } \\
\text { correio electrónico. }\end{array}$ & 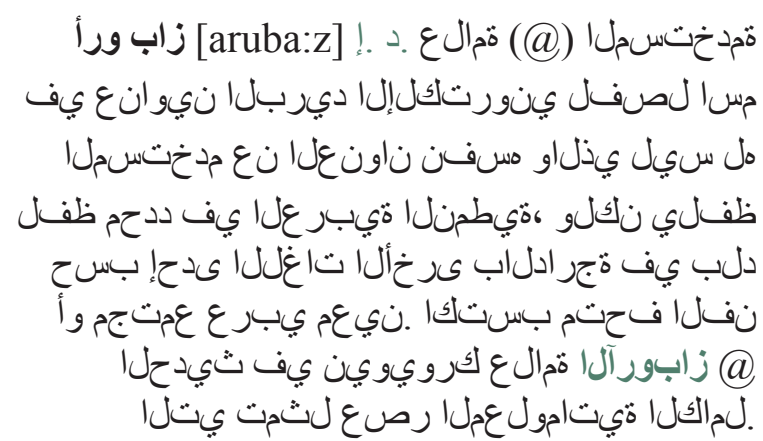 \\
\hline
\end{tabular}

3. Componentes da placa mãe:

\begin{tabular}{|c|c|}
\hline Português & Árabe \\
\hline $\begin{array}{l}\text { processador [prusəse ' dor] n.m. circuito } \\
\text { integrado que constitui o órgão central do } \\
\text { computador e que tem capacidade para } \\
\text { obter, descodificar e executar instruções. As } \\
\text { principais funções de um processador são: } \\
\text { a execução das aplicações e a coordenação } \\
\text { dos diferentes dispositivos contidos no } \\
\text { equipamento. }\end{array}$ & 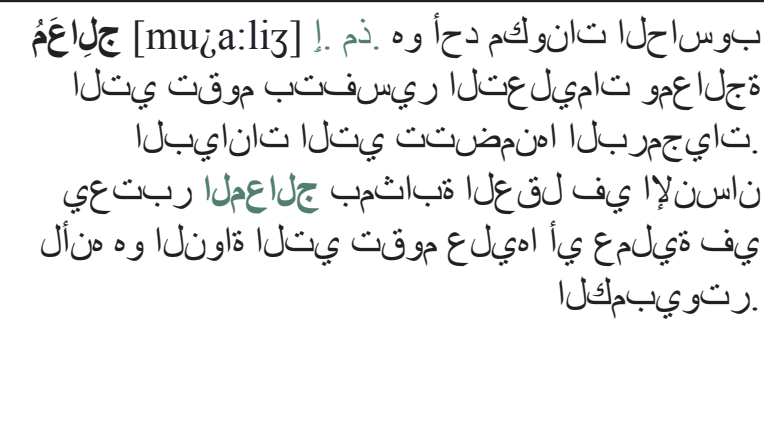 \\
\hline $\begin{array}{l}\text { microprocessador [mikroprusəse' dor] } \\
\text { ou microchip [mikro' 'jip] } n . m \text {. circuito } \\
\text { integrado de complexo que efectua as } \\
\text { operações básicas de um microcomputador. } \\
\text { O microprocessador escolhido determina } \\
\text { a capacidade de processamento do } \\
\text { computador. }\end{array}$ & 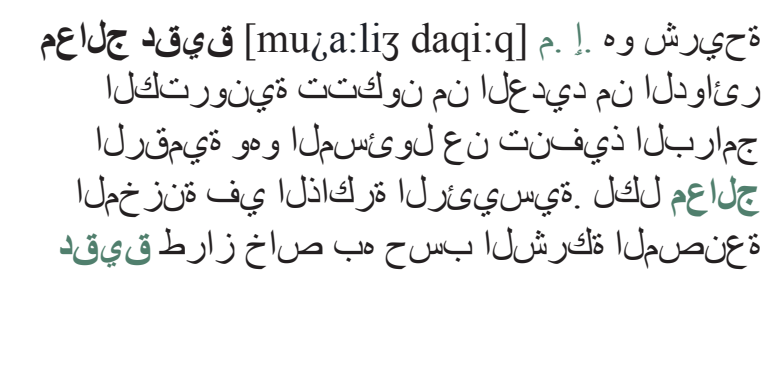 \\
\hline
\end{tabular}

OKAB, A. Abordagem semântica e morfológica a termos informáticos num dicionário bilingue Português Europeu - Árabe Padrão 
Linha D’Água (Online), São Paulo, v. 33, n. 1, p. 31-48, jan.-abr. 2020

4. Unidades de medida informática:

\begin{tabular}{|c|c|}
\hline Português & Árabe \\
\hline $\begin{array}{l}\text { byte ['bajt] } n . m \text {. unidade básica de } \\
\text { informação constituída por } 8 \text { bits: A melhor } \\
\text { forma de optimizar a RAM até ao último } \\
\text { byte disponivel é através da compra de um } \\
\text { bom gestor de memória. }\end{array}$ & 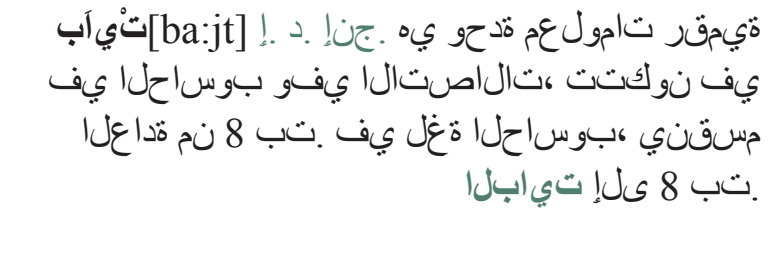 \\
\hline $\begin{array}{l}\text { megabit [mege 'bit] } n . m \text {. medida de } \\
\text { capacidade de memória correspondente } \\
\text { a } 1024 \text { kilobits. O fluxo de dados nos } \\
\text { computadores é medido por megabit. }\end{array}$ & 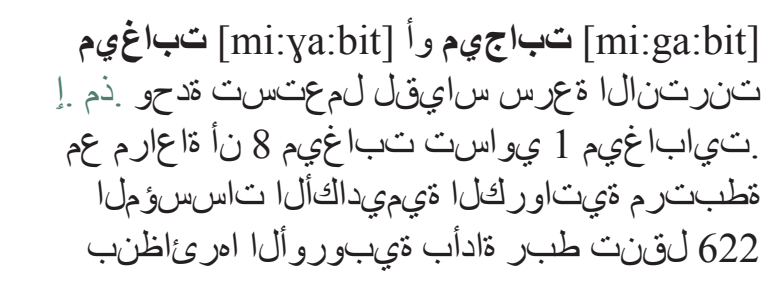 \\
\hline $\begin{array}{l}\text { megabyte [mege 'bajt] } n . m \text {. unidade de } \\
\text { medida de informação, equivalente a um } \\
\text { milhão de bytes. O megabyte é usado para } \\
\text { medir o tamanho da memória e do espaço } \\
\text { de armazenamento de um hardware. }\end{array}$ & 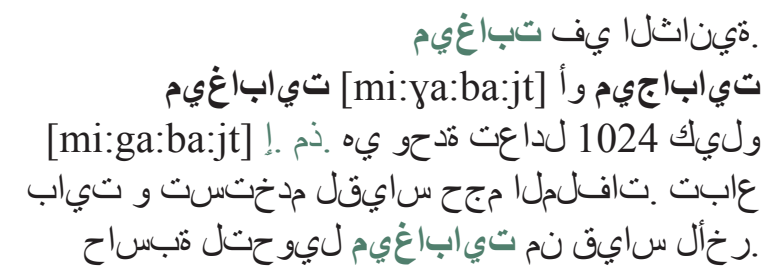 \\
\hline
\end{tabular}

\section{Profissionais informáticos}

\begin{tabular}{|c|c|}
\hline Português & Árabe \\
\hline $\begin{array}{l}\text { cracker ['kraker] } n \text {. pessoa que quebra } \\
\text { a segurança de sistemas informáticos. } \\
\text { Muitos crackers aconselham empresas na } \\
\text { segurança dos computadores. } \\
\text { programador [prugreme' dor] n.m. pessoa } \\
\text { que desenvolve e aperfeiçoa programas de } \\
\text { computador. Com certeza, ser programador } \\
\text { é uma alternativa interessante e vantajosa } \\
\text { no mercado atual. } \\
\text { webmaster [web' mafter] n. pessoa } \\
\text { responsável pela edição ou pela } \\
\text { administração de um site na Internet. Nos } \\
\text { dias atuais, o webmaster de ponta trabalha } \\
\text { com criação de sistemas com usabilidade } \\
\text { para deficientes físicos e visuais. }\end{array}$ & 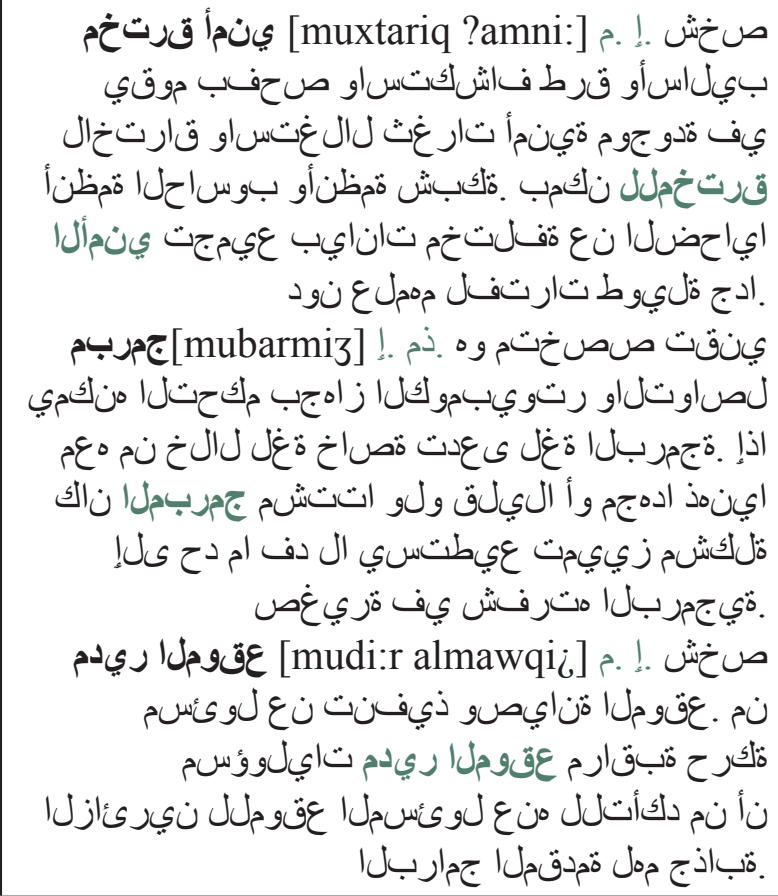 \\
\hline
\end{tabular}

OKAB, A. Abordagem semântica e morfológica a termos informáticos num dicionário bilingue Português Europeu - Árabe Padrão 
Linha D’Água (Online), São Paulo, v. 33, n. 1, p. 31-48, jan.-abr. 2020

\section{Ação informática:}

\begin{tabular}{|c|c|}
\hline Português & Árabe \\
\hline $\begin{array}{l}\left.\left.\text { crashar [kre' } \int a r\right]\right] ~ v \text { trans. dir. interromper- } \\
\text { se inesperadamente um programa } \\
\text { informático. Aquele impulso consegue } \\
\text { crashar qualquer computador. } \\
\text { descompactar [də]kõpe'ktar] v.trans. dir. } \\
\text { restablecer tamanho original dum ficheiro } \\
\text { que foi comprimido para ocupar menos } \\
\text { espaço num suporte informático. Sempre use } \\
\text { um aplicativo confiável para descompactar } \\
\text { o arquivo ZIP. } \\
\text { scanear [ske'njar] v.trans.dir. converter } \\
\text { texto ou imagem impressos em dados } \\
\text { digitais, passíveis de serem interpretados por } \\
\text { um computador, utilizando um aparelho de } \\
\text { leitura ótica como um scanner. Precisamos } \\
\text { de uma solução para que seja possivel } \\
\text { scanear diretamente documentos e fazer } \\
\text { recorte e salvar. }\end{array}$ & 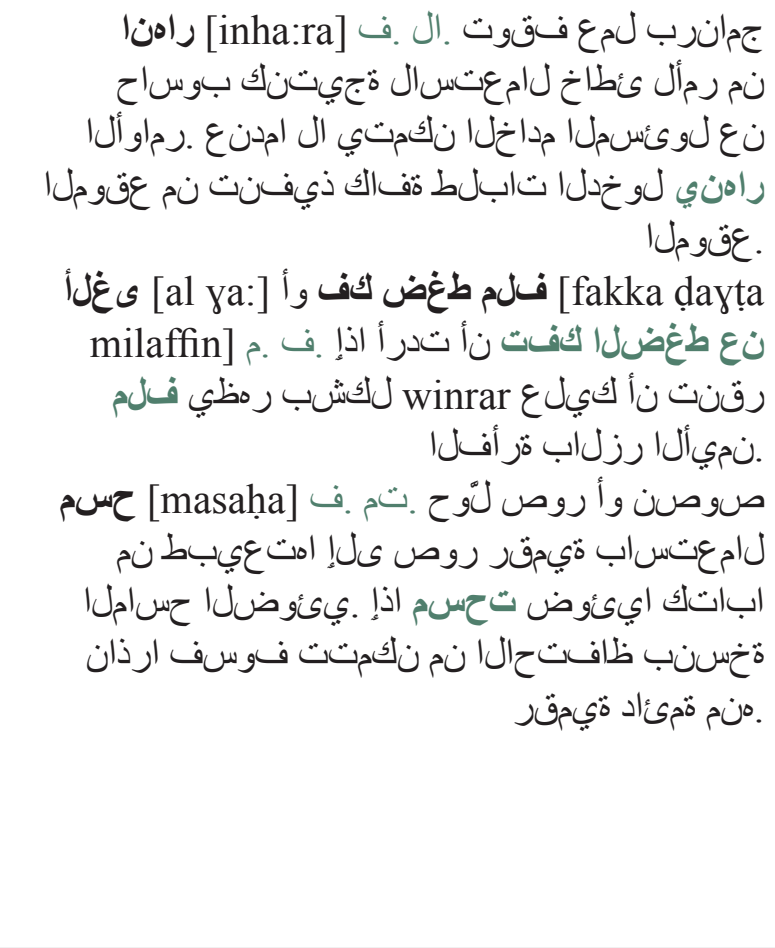 \\
\hline
\end{tabular}

7. Algumas siglas - termos:

\begin{tabular}{|c|c|}
\hline Portu & rabe \\
\hline $\begin{array}{l}\text { PDF é um formato de ficheiro único que } \\
\text { preserva as característica originais de seu } \\
\text { documento independente da fonte que o } \\
\text { gerou (Sigla de Portable Document Format). } \\
\text { Os PDFs podem ser impressos exatamente } \\
\text { da mesma maneira em qualquer impressora, } \\
\text { pois a sua formatação mantêm-se fixa. } \\
\text { RAM memória do computador que armazena } \\
\text { dados temporariamente (Sigla de Random } \\
\text { Access Memory). A RAM é uma peça que } \\
\text { armazena dados de programas em execução } \\
\text { enquanto o computador está ligado. }\end{array}$ & 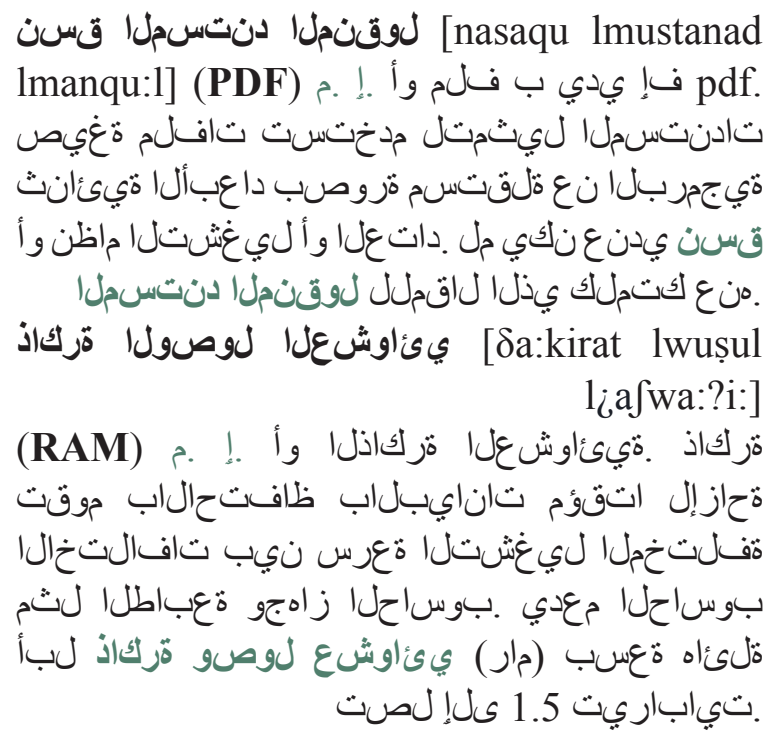 \\
\hline
\end{tabular}

(continua)

OKAB, A. Abordagem semântica e morfológica a termos informáticos num dicionário bilingue Português Europeu - Árabe Padrão 
Linha D'Água (Online), São Paulo, v. 33, n. 1, p. 31-48, jan.-abr. 2020

(continuação)

\begin{tabular}{|c|c|}
\hline Português & Árabe \\
\hline $\begin{array}{l}\text { URL sistema que localiza recursos na internet } \\
\text { através da atribuição de nomes e endereços } \\
\text { (Sigla de Uniform Resource Locator). Uma } \\
\text { URL bem estruturada pode causar grande } \\
\text { impacto na estratégia digital de qualquer } \\
\text { negócio. } \\
\text { USB tipo de conexão para ligação de } \\
\text { periféricos (impressoras, scanners, etc.) } \\
\text { (Sigla de Universal Serial Bus). A atual } \\
\text { versão de USB entrou no mercado de forma } \\
\text { efetiva no final de } 2001 \text {. }\end{array}$ & 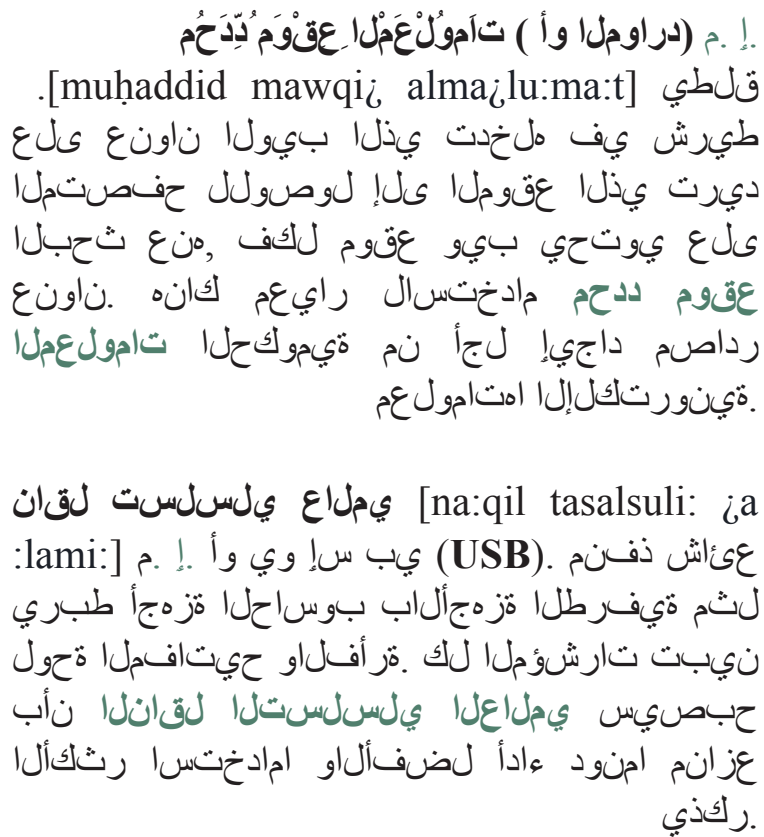 \\
\hline
\end{tabular}

Neste corpus dominam, portanto, muitos empréstimos crudos no português língua de partida, incorporados tais como são no inglês e às vezes com uma ligeira adaptação fonética. $\mathrm{O}$ fato de não serem aportuguesados morfologicamente esse tipo de xenotermos levou a investigadora Margarita Correia (2006) a prever uma possível influência do inglês na morfologia das línguas acolhedoras de vocabulários de especialidade dessa língua:

Trazer à consideração do auditório a hipótese de que línguas minorizadas, como é ocaso do português na Europa, estejam a ser descaracterizadas, já não apenas pela entrada maciça de termos de língua inglesa, mas também pela criação neológica com recurso quase exclusivo a mecanismos e operadores que têm cognatos em língua inglesa. Dito de outro modo, ponho a hipótese de as nossas línguas estarem a ser afectadas no seu âmago, isto é, na sua estrutura morfológica. (CORREIA, 2006, p. 32).

Quanto ao árabe padrão, o corpus representa uma seleção com base em textos de divulgação numérica e glossários terminológicos como já foram acima referidos. No entanto, a diglossia no mundo árabe faz com que, em paralelo aos decalques ou

OKAB, A. Abordagem semântica e morfológica a termos informáticos num dicionário bilingue Português Europeu - Árabe Padrão 
Linha D'Água (Online), São Paulo, v. 33, n. 1, p. 31-48, jan.-abr. 2020

traduções literais do sistema estandardizado, as falas locais utilizem sobretudo empréstimos crudos não só entre especialistas, mas também na linguagem do dia-a-dia.

\section{Análise semântica e morfológica}

Quer nas unidades terminológicas quer nas unidades lexicais, uma análise semântica permite essencialmente descrever como as unidades em causa estabelecem entre si determinadas relações semânticas que constituem uma estrutura de significados organizados numa rede de conhecimento, como é o caso neste estudo, focado na terminologia informática. Quanto à morfologia das palavras analisadas semanticamente, constitui um aspeto complementar que visa descrever as variações morfológicas dos empréstimos ingleses no português europeu, que às vezes nem sofrem uma modificação articulatória, assim como dar observações sobre os decalques árabes que são na sua imensa maioria sintagmas terminológicos que resultam da tradução de termos simples ou da siglação da língua dominante no domínio da tecnologia informática.

Como não tencionamos, no quadro desta perspetivação de lexicografia de especialidade num dicionário bilingue Português Europeu - Árabe Padrão, estudar todos os níveis que envolve a estruturação semântica dos empréstimos informáticos, empregados em ambas as línguas em foco, lançamos mão do modelo componencial do linguista francês Pottier ${ }^{2}$ para evidenciar os traços sêmicos que compõem as terminologias das sete subclasses que formam o conjunto de vinte termos de uso frequente nessa linguagem para fins específicos. Esse célebre método analítico nos anos 60 consiste em decompor o conteúdo semântico das unidades léxicas dum mesmo campo semântico em semas ou traços sêmicos, para diferenciar as palavras pertencentes à mesma esfera semântica. Naquela altura, a proposta de Pottier (1964) foi criticada por ter tido em conta os mínimos traços de conteúdo extralinguístico na análise do seu campo lexical dos nomes das cadeiras. Mas com o decorrer dos anos, o terminólogo alemão Martin Hummel (2009) afirmou que

2 Pottier, Bernard. Vers une sémantique moderne. Travaux de linguistique et de littérature de Strasbourg II, 1964, p. 107-137.

OKAB, A. Abordagem semântica e morfológica a termos informáticos num dicionário bilingue Português Europeu - Árabe Padrão 
Linha D’Água (Online), São Paulo, v. 33, n. 1, p. 31-48, jan.-abr. 2020

não se pode considerar errada a validade desses traços no nosso conhecimento, salientando na citação abaixo a importância da sua função na comunicação:

In this sense, the structural assumption of intra-linguistic features is right. They do not differ in nature of from other features of our knowledge, but only by their function in linguistic communication, for instance, if a word presupposes a featu for designation. In other words, when a meaning presupposes "four legs" in the referential process, then the extra-linguistic feature "four legs" has been integrate cognitively as semantic feature in our mental concept. This way; the concept has mental reality on its own right. (HUMMEL, 2009, p. 115).

Em consequência, a aplicação da análise de Pottier (1964) para explicitar as relações semânticas das unidades analisadas neste trabalho não coloca problemas para determinar o significado nuclear de cada termo, e numa perspetivação terminológica, como afirma Hummel (2009, p. 110), "a primeira função de uma palavra é identificar o significado e, em segundo lugar, é ativar as grandes partes das redes cognitivas que rodeiam o seu significado principal".

A aplicação da decomposição dos termos dos sete subcampos terminológicos, que apresentei na primeira parte, para caracterizar os seus membros constitutivos em semas ou traços mínimos de sentido que permitem estabelecer diferenças entre unidades terminológicas do mesmo conjunto, será feita, a seguir, em forma de quadros sêmicos:

- Subconjunto de nomes de componentes materiais ou imateriais do computador:

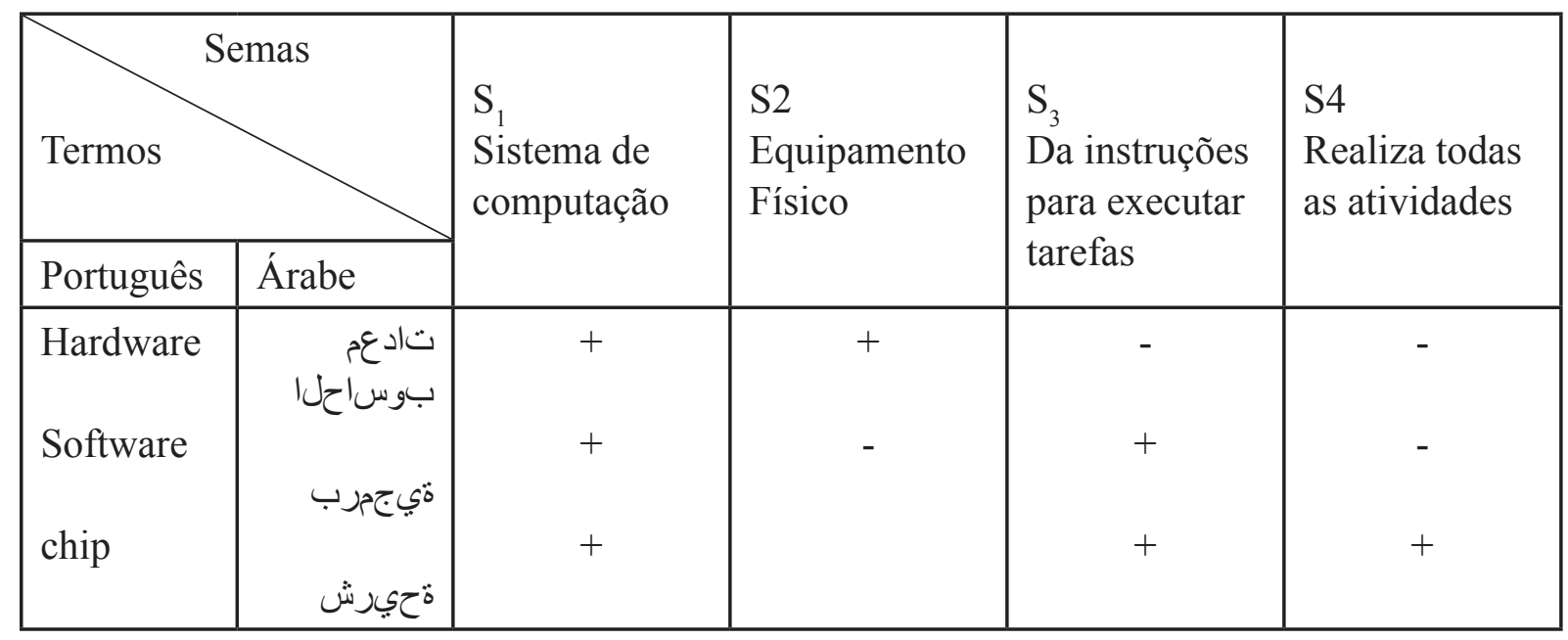

OKAB, A. Abordagem semântica e morfológica a termos informáticos num dicionário bilingue Português Europeu - Árabe Padrão 
Linha D’Água (Online), São Paulo, v. 33, n. 1, p. 31-48, jan.-abr. 2020

- Subconjunto de interfaces gráficas e sinais:

\begin{tabular}{|c|c|c|c|c|}
\hline \multicolumn{2}{|c|}{ Termos Semas } & \multirow{2}{*}{$\begin{array}{l}\mathrm{S}_{1} \\
\text { Interface gráfico ou } \\
\text { sinal }\end{array}$} & \multirow{2}{*}{$\begin{array}{l}\text { S2 } \\
\text { Mostra ícone }\end{array}$} & \multirow{2}{*}{$\begin{array}{l}\mathrm{S}_{3} \\
\text { Símbolo do correio } \\
\text { eletrónico }\end{array}$} \\
\hline Português & Árabe & & & \\
\hline Desktop & بتس & + & + & - \\
\hline arroba & زابورأ & + & - & + \\
\hline
\end{tabular}

- Subconjunto de componente da placa da mãe:

\begin{tabular}{|c|c|c|c|c|}
\hline \multicolumn{2}{|l|}{ Semas } & \multirow{2}{*}{$\begin{array}{l}\mathrm{S}_{1} \\
\text { Componente da } \\
\text { placa da mãe }\end{array}$} & \multirow{2}{*}{$\begin{array}{l}\text { S2 } \\
\text { Descodificação e } \\
\text { execução }\end{array}$} & \multirow{2}{*}{$\begin{array}{l}\mathrm{S}_{3} \\
\text { Pequeno circuito } \\
\text { microscópico }\end{array}$} \\
\hline Português & Árabe & & & \\
\hline Processador & جل & + & + & - \\
\hline Microprocessador & قجيقد ج & + & + & + \\
\hline
\end{tabular}

- Subconjunto de unidades de medida informática:

\begin{tabular}{|c|c|c|c|c|c|}
\hline Termos & mas & $\begin{array}{l}\mathrm{S}_{1} \\
\text { Unidade de } \\
\text { medida basilar }\end{array}$ & $\begin{array}{l}\mathrm{S} 2 \\
8 \text { bits }\end{array}$ & $\begin{array}{l}\mathrm{S}_{3} \\
1024 \text { kilobits }\end{array}$ & $\begin{array}{l}\text { S4 } \\
1 \text { milhão de } \\
\text { bits }\end{array}$ \\
\hline Português & Árabe & & & & \\
\hline Byte & تُّياب & + & + & - & - \\
\hline Megabit & تباغيم & + & - & + & - \\
\hline Megabyte & تياباغيم & + & - & - & + \\
\hline
\end{tabular}

OKAB, A. Abordagem semântica e morfológica a termos informáticos num dicionário bilingue Português Europeu - Árabe Padrão 
Linha D’Água (Online), São Paulo, v. 33, n. 1, p. 31-48, jan.-abr. 2020

- Subconjunto de profissionais informáticos:

\begin{tabular}{|c|c|c|c|c|c|}
\hline \multicolumn{2}{|c|}{ Sermos } & \multirow[t]{2}{*}{$\begin{array}{l}\mathrm{S}_{1} \\
\text { Profissão de } \\
\text { informático }\end{array}$} & \multirow[t]{2}{*}{$\begin{array}{l}\text { S2 } \\
\text { Programação }\end{array}$} & \multirow{2}{*}{$\begin{array}{l}\mathrm{S}_{3} \\
\text { Desenho e } \\
\text { desenvolvimento } \\
\text { de páginas }\end{array}$} & \multirow[t]{2}{*}{$\begin{array}{l}\text { S4 } \\
\text { Atividade } \\
\text { ilegal }\end{array}$} \\
\hline Português & Árabe & & & & \\
\hline Cracker & قرنمأ & + & & - & + \\
\hline Programador & جمربم & + & + & - & - \\
\hline Webmaster & عقوملما & + & - & + & - \\
\hline
\end{tabular}

- Conjunto de verbos ações - processos:

\begin{tabular}{|c|c|c|c|c|c|}
\hline Termos & & \multirow{2}{*}{$\begin{array}{l}\mathrm{S}_{1} \\
\text { Ação- } \\
\text { processo } \\
\text { informática }\end{array}$} & \multirow[t]{2}{*}{$\begin{array}{l}\text { S2 } \\
\text { Interrupção do } \\
\text { programa }\end{array}$} & \multirow[t]{2}{*}{$\begin{array}{l}\mathrm{S}_{3} \\
\text { Descompressão } \\
\text { de ficheiro }\end{array}$} & \multirow[t]{2}{*}{$\begin{array}{l}\text { S4 } \\
\text { Conversão em } \\
\text { dados digitais }\end{array}$} \\
\hline Português & Árabe & & & & \\
\hline Crashar & رامنا & + & + & - & - \\
\hline Descompactar & 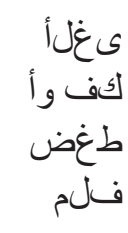 & + & - & + & - \\
\hline Scanear & عسم & + & - & - & + \\
\hline
\end{tabular}

OKAB, A. Abordagem semântica e morfológica a termos informáticos num dicionário bilingue Português Europeu - Árabe Padrão 
Linha D’Água (Online), São Paulo, v. 33, n. 1, p. 31-48, jan.-abr. 2020

- Algumas siglas - termos:

\begin{tabular}{|c|c|c|c|c|c|c|}
\hline \multicolumn{2}{|c|}{ Termos Semas } & \multirow[t]{2}{*}{$\begin{array}{l}\mathrm{S}_{1} \\
\text { Componente } \\
\text { de } \\
\text { Computação }\end{array}$} & \multirow[t]{2}{*}{$\begin{array}{l}\mathrm{S}_{2} \\
\text { Formato de } \\
\text { documento } \\
\text { portátil }\end{array}$} & \multirow[t]{2}{*}{$\begin{array}{l}\mathrm{S}_{3} \\
\text { Memória } \\
\text { temporal }\end{array}$} & \multirow[t]{2}{*}{$\begin{array}{l}\mathrm{S}_{4} \\
\text { Localizador } \\
\text { Universal } \\
\text { de recursos }\end{array}$} & \multirow[t]{2}{*}{$\begin{array}{l}\mathrm{S}_{5} \\
\text { Conector } \\
\text { periférico }\end{array}$} \\
\hline Português & Árabe & & & & & \\
\hline PDF & لد دنسن & + & + & - & - & - \\
\hline RAM & لزوكاذ & + & - & + & - & - \\
\hline URL & 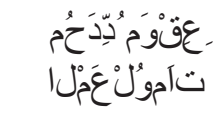 & + & - & - & + & - \\
\hline USB & ليقانسان & + & - & - & - & + \\
\hline
\end{tabular}

Do ponto de vista do número de termos que compõem os sete conjuntos, cuja divisão em mínimas características semânticas foi feita acima, existem quatro grupos com três termos, dois com dois candidatos terminológicos e um com quatro unidades. $\mathrm{O}$ conjunto dos semas mínimos dos quais precisa a desmembração do conteúdo desses é:

$\mathrm{C}(3$ termos $)=\mathrm{S}_{1+} \mathrm{S}_{2+} \mathrm{S}_{3+} \mathrm{S}_{4}$
$\mathrm{C}(2$ termos $)=\mathrm{S}_{1+} \mathrm{S}_{2+} \mathrm{S}_{3}$
$\mathrm{C}(4$ termos $)=\mathrm{S}_{1+} \mathrm{S}_{2+} \mathrm{S}_{3+} \mathrm{S}_{4+} \mathrm{S}_{5}$

O que se pode deduzir dessa decomposição de unidades terminológicas em semas é que o número de semas que opõem os elementos que partilham um traço comum coincide exatamente com as unidades opostas; isso significa que a

OKAB, A. Abordagem semântica e morfológica a termos informáticos num dicionário bilingue Português Europeu - Árabe Padrão 
Linha D’Água (Online), São Paulo, v. 33, n. 1, p. 31-48, jan.-abr. 2020

designação terminológica é um procedimento linguístico que une conceitos ideais a objetos e funções reais.

A variação morfológica dos termos de origem inglesa no corpus de português europeu permite-nos formular algumas observações sobre o seu comportamento na língua acolhedora. As formas presentes nos exemplos apresentam dados que contêm informações sobre os seguintes aspectos morfológicos:

- As palavras inglesas, sem marcas de gênero masculino ou feminino no seu sistema, adquirem o gênero masculino mediante o artigo português o: ochip, 0 desktop, o hardware e quando pluralizam levam a marca gráfica $s$, que segundo o contexto silábico ou articulação sintática, é pronunciada como as consoantes palatais [ $[$ ] ou [3]: os chips, os desktops, os hardwares.

- Na sufixação nominal dos nomes de profissionais ou circuitos que executam operações no computador, os substantivos de origem inglesa foram integrados no português com o sufixo [dor] portador do significado de ação como nas seguintes unidades: programador, processador e microprocessador.

- Na sufixação verbal, o aportuguesamento dum verbo, a partir duma base verbal inglesa usada na língua de especialidade em causa, adquire marcas infinitivas da língua acolhedora:

a - a terminação [ar] para uma ação simples como em crashar e descompactar,

b - a desinência [ear] para exprimir uma significação frequentativa na base formativa como em escanear.

No árabe padrão, que é a língua das mídias e o veículo literário e científico nos países árabes, as palavras que equivalem a termos anglo-saxónicos pertencem a unidades lexicais do tesouro lexicográfico árabe, no qual se utilizam para exprimir conceitos gerais e, portanto, constituem traduções literais, para não incorporar termos crudos numa língua com caracteres alfabéticos próprios e muito afastada da família indo-europeia.

OKAB, A. Abordagem semântica e morfológica a termos informáticos num dicionário bilingue Português Europeu - Árabe Padrão 
Linha D’Água (Online), São Paulo, v. 33, n. 1, p. 31-48, jan.-abr. 2020

Assim, só há sete termos simples entre os quais existe [aruba:z] زاب ورأ uma variante francesa do anglicismo $a r r o b a^{3}$, que é um sinal de correio eletrónico. Os outros estão distribuídos conforme as suas categorias morfossintáticas em:

- 4 nomes de formas nominais e verbais árabes:

\begin{tabular}{|c|c|}
\hline Inglês/Português & Árabe Padrão \\
\hline $\begin{array}{l}\text { Chip } \\
\text { Software } \\
\text { Processador } \\
\text { Programador }\end{array}$ & 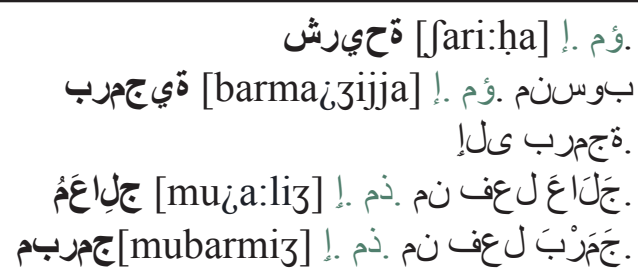 \\
\hline
\end{tabular}

- 2 verbos:

\begin{tabular}{|c|c|}
\hline Inglês/Português & Árabe Padrão \\
\hline $\begin{array}{l}\text { Crash/Crashar } \\
\text { Scan/Scanear }\end{array}$ & 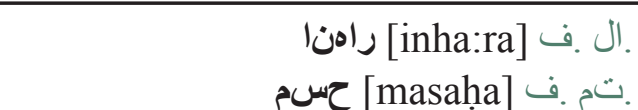 \\
\hline
\end{tabular}

Os 13 correspondentes terminológicos do português no nosso corpus, em uso no árabe estandardizado, dividem-se em duas classes de empréstimos:

- 3 termos crudos, que pertencem ao campo semântico das medidas de informação, só transliterados em alfabeto arábico e ligeiramente adaptados a articulação árabe:

\begin{tabular}{|c|c|}
\hline Inglês/Português & Árabe Padrão \\
\hline Byte & 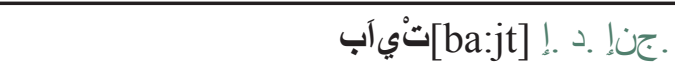 \\
\hline Megabit & 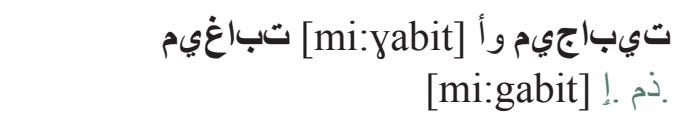 \\
\hline Megabyte & 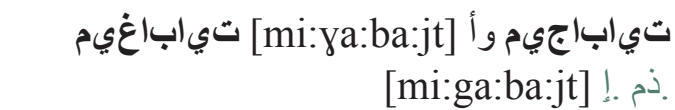 \\
\hline
\end{tabular}

3 A palavra arroba é um arabismo usado no espanhol e no portugês para se referir a uma medida antiga de peso.

OKAB, A. Abordagem semântica e morfológica a termos informáticos num dicionário bilingue Português Europeu - Árabe Padrão 
Linha D'Água (Online), São Paulo, v. 33, n. 1, p. 31-48, jan.-abr. 2020

- 4 sintagmas terminológicos, que procedem da siglação na língua doadora e cujas siglas não são automaticamente transliteradas senão que se usam nas suas siglas inglesas acompanhadas de conceitos literais da língua acolhedora para dar forma linguística a sua significação terminológica:

\begin{tabular}{|c|c|}
\hline Inglês/Português & Árabe Padrão \\
\hline PDF & 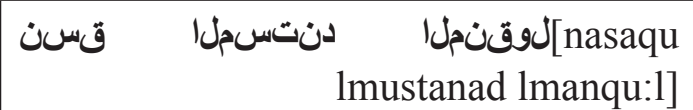 \\
\hline RAM & 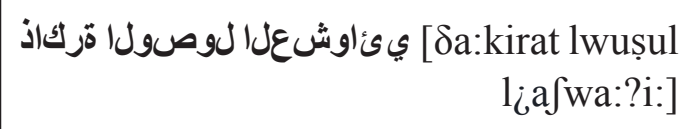 \\
\hline URL & 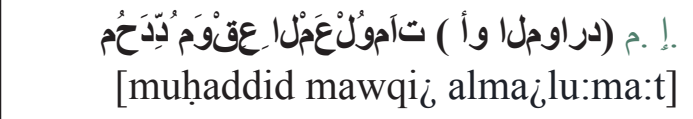 \\
\hline USB & 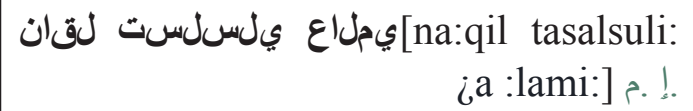 \\
\hline
\end{tabular}

Os 6 elementos restantes são sintagmas terminológicos que servem para exprimir necessidades semânticas que estão estreitamente em relação de dependência com objetos, funções e profissões informáticas:

\begin{tabular}{|c|c|}
\hline Inglês/Português & Árabe Padrão \\
\hline Desktop & 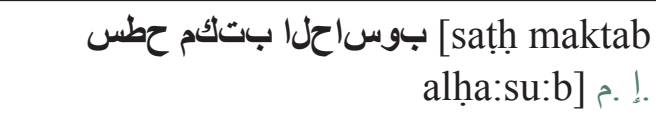 \\
\hline Hardware & • م إ ] بوساحلا تادعم [mu_idda:t alha:su:b] \\
\hline Microprocessador/Microchip & 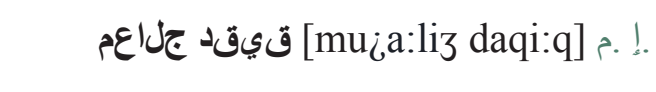 \\
\hline Webmaster & 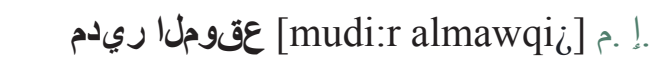 \\
\hline Cracker & 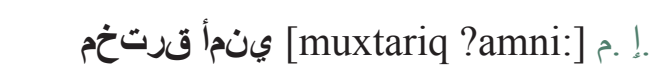 \\
\hline Descompactar & 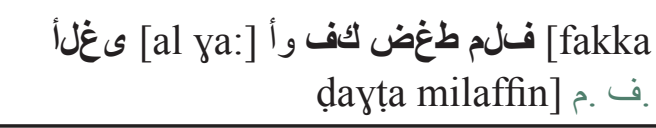 \\
\hline
\end{tabular}

OKAB, A. Abordagem semântica e morfológica a termos informáticos num dicionário bilingue Português Europeu - Árabe Padrão 
Linha D’Água (Online), São Paulo, v. 33, n. 1, p. 31-48, jan.-abr. 2020

\section{Considerações finais}

Em jeito de conclusão, os termos da informática estudados numa abordagem bilingue Português Europeu - Árabe Padrão revelam que a solução do português, por economia da linguagem, é usar os empréstimos do inglês com apenas alguma alteração na pronúncia ou na forma, enquanto no árabe padrão a tendência é arabizar recorrendo a decalques semânticos com palavras do seu próprio tesouro lexical, por se tratar duma língua padronizada, visto que as línguas de fala espontânea nos países árabes usam sobretudo os empréstimos do inglês.

A semântica dos termos em causa, analisada no quadro da decomposição sêmica das unidades terminológicas, agrupadas em subcampos terminológicos cujos componentes partilham uma propriedade semântica comum, tem demonstrado que essas unidades semio-linguísicas se diferenciam entre si por uma só dimensão semântica, porque os seus conceitos se estruturam em derredor de objetos, funções e profissões, dado que se trata de um domínio técnico-informático.

A morfologia dos empréstimos crudos do português não obedece a um mecanismo automático de aportuguesamento, e as poucas marcas morfológicas da língua portuguesa ficam atestadas, no corpus recolhido, por verbos, nomes de funções e de algumas atividades profissionais. Em relação a esse ponto, só um corpus exaustivo pode revelar se a morfologia do português é permeável perante a invasão de neologismos científicos do inglês.

\section{Referências}

AL-AJMI, H. Dicionário de termos técnicos da informática Inglês-Arabe. Kuwait: Universidade de Kuwait, 2017-2018.

ALVES, L. M. Empréstimos nas línguas de especialidade: algumas considerações. In: Ciência da Informação, Brasília: Instituto Brasileiro de Informação em Ciência e tecnologia (Ibict), vol. 24, n. 3, 1995, p. 319-321.

ASSIRATI, E. T. Neologismo por empréstimo na informática. In: Alfa/Revista de Linguistica, São Paulo, vol. 42, 1998, p. 121-145.

OKAB, A. Abordagem semântica e morfológica a termos informáticos num dicionário bilingue Português Europeu - Árabe Padrão 
Linha D'Água (Online), São Paulo, v. 33, n. 1, p. 31-48, jan.-abr. 2020

BERTELS, A. Étudier la sémantique des termes techniques : des théories à la pratique. In : $A c$ -

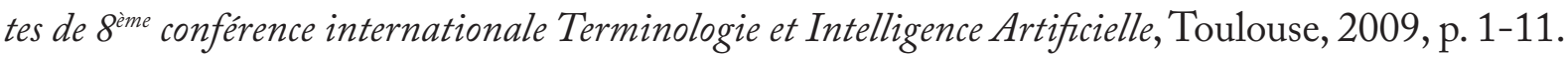

CAMPENHOUDT, M. V. Pour une approche sémantique du terme et de ses équivalents. In: International Journal of Lexicography, Oxford University Press, XIV, 3 September, 2001, p. 1-26.

CIRO, L. A.; VILA RUBIO, N. El préstamo en el léxico de la informática e Internet en el ámbito hispánico. Revista Virtual Universidad Católica del Norte, n. 46, 2015, 129-145.

CORREIA, M. Morfologia e terminologia: marcas morfológicas da génese do vocabulário da Náutica português». In: M. T. Cabré, R. Estopà \& C. Tebé (eds.). La terminologia en el siglo XXI - Contribución a la Cultura de la Paz, la Diversidad y la Sostenibilidad (Atas del LX Simpósio Iberoamericano de Terminología RITERM04). Barcelona: IULA / Universitat Pompeu Fabra, 2006, p. 31-52.

FASSI FEHRI, A. Lexique d'informatique Français - Anglais - Arabe. Rabat : Publications de l'Institut d'Études et de Recherches pour l'Arabisation, Université Mohammed V.

HUMMEL, M. Semantics, terminology, and the impact of history and culture on socioeconomic terms. In: Fachsprache, n. 3-4, 2009, p. 110-125.

MARTÍNEZ MOTOS, R. Los campos semánticos y la terminología bilingüe. In: El diccionario como puente entre las lenguas y culturas del mundo. Actas del II Congreso Internacional de Lexicografía Hispánica. Edición digital: http://www.cervantesvirtual.com/nd/ ark:59851/bmc697ml, p. 742-746.

MORAIS, I.T. Algumas considerações sobre línguas de especialidade e seus processos lexicogénicos. In: Revista Máthesis, n. 12, 2003, p. 113-130. Lisboa: Universidade Católica Portuguesa.

POTTIER, B. Vers une sémantique moderne. In : Travaux de Linguistique et de Littérature de Strasbourg II, 1964, p. 107-137.

POTTIER, B. Comment dénommer les sèmes. In : Bulletin du Groupe de recherches sémio-linguistiques (EHESS), Institut de la langue française (CNRS), n. 13, 1980, p. 21-29.

RAIMUNDO, E. M., CERVANTES, B. M., PEREIRA, L. M. Análise terminológica: termos e contextos. In: Anais do V Selisigno e VI Simpósio de Leitura da Universidade Estatual de Londrina, 2006, p. 1-6.

OKAB, A. Abordagem semântica e morfológica a termos informáticos num dicionário bilingue Português Europeu - Árabe Padrão 
Linha D’Água (Online), São Paulo, v. 33, n. 1, p. 31-48, jan.-abr. 2020

SERRANO, O. R. Analyse sémantico-lexicale et terminologique. In Revista Folios, n. 47, 2018, p. 153-163. Bogotá: Universidad Pedagógica Nacional.

TTAOUALBA, M. Dicionário de Abu Ghazala das técnicas informáticas e da comunicaşão Árabe -Inglês. Jordânia: Editora Associação de Contabilistas, 2012.

TTAMIMI, A. Termos de Internet e da informática usados no mundo e suas definições. Jordânia: Dar Oussama, 2009.

Recebido: 30/11/2019.

Aprovado: 16/01/2020.

OKAB, A. Abordagem semântica e morfológica a termos informáticos num dicionário bilingue Português Europeu - Árabe Padrão 